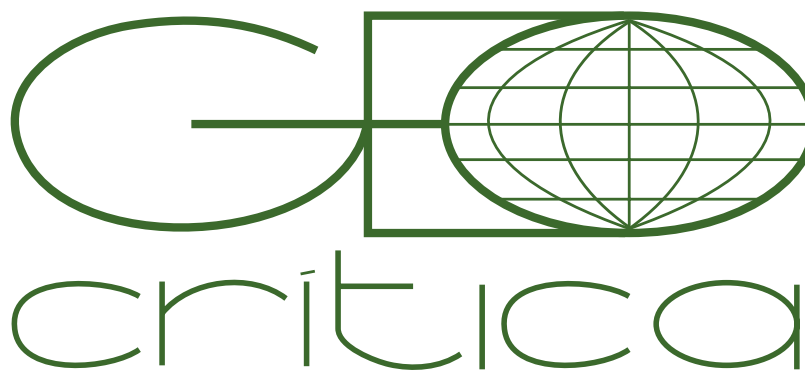

Revista Electrónica de Geografía y Ciencias Sociales Universitat de Barcelona

\title{
¿ALTERNATIVA O ADAPTACIÓN? LOS GRUPOS DE CONSUMO DE ALIMENTOS ECOLÓGICOS EN EL ÁREA URBANA DE ALICANTE
}

\author{
José Luis Sánchez Hernández \\ Universidad de Salamanca \\ jlsh@usal.es
}

\author{
Ana Espinosa Seguí \\ Universidad de Alicante \\ anaretailing@yahoo.es
}

Recibido: 30 Noviembre 2018; Devuelto para correcciones: 11 Abril 2019; Aceptado: 19 Septiembre 2019

\begin{abstract}
¿Alternativa o adaptación? Los grupos de consumo de alimentos ecológicos en el área urbana de Alicante (Resumen)

Los grupos de consumo ecológico constituyen una modalidad de coordinación entre productores y consumidores que suscriben los principios de la agroecología y la soberanía alimentaria. Aunque se trata de una opción minoritaria dentro del nicho de mercado de los alimentos ecológicos, algunos de ellos están creciendo en número de socios y volumen de actividad durante los últimos años. Esta expansión cuantitativa se relaciona con la entrada de miembros interesados por el cuidado de la salud a través de la alimentación, contrastando con los objetivos de transformación social y política impulsados con la fundación de estos grupos de consumo. El artículo constata este proceso de neo-convencionalización de las prácticas alimentarias alternativas en el área metropolitana de Alicante (España).
\end{abstract}

Palabras clave: alimentos ecológicos, grupos de consumo, economías alternativas, convencionalización

\footnotetext{
Alternative or adaptation? Organic food consumer groups in Alicante (Spain) (Abstract)

Organic food consumer groups connect producers and consumers who subscribe ideas about agroecology and food sovereignty. Their share of the whole organic food market is really small, but some of these groups are experiencing a quick growth in their membership and economic turnover too. This quantitative growth leads is mostly related to the interest of new members on the relationship between food and health. However, this new profile in membership sharply contrasts to the claims for social and political change that prevailed among founders of these consumer groups. This article scrutinizes this neo-conventionalization process of alternative food practices in the metropolitan area of Alicante (Spain).
}

Keywords: organic food, consumer groups, diverse economies, conventionalization 
En los países desarrollados se ha extendido durante las últimas cuatro décadas la preocupación por la relación entre alimentación, salud y medio ambiente' ${ }^{1}$ A ojos de muchos consumidores, los alimentos trascienden la función nutritiva y constituyen un medio para cuidar de su salud y contribuir a la transición hacia un sistema socioeconómico más justo y sostenible.

Las evidencias sobre los efectos perniciosos que las cadenas agroalimentarias globales ${ }^{2}$ tienen sobre la salud y la naturaleza pueden justificar la adquisición de alimentos sin aditivos químicos. Pero también la concienciación social sobre la necesidad de avanzar hacia la soberanía alimentaria (que La Vía Campesina define como la capacidad de los pueblos para decidir sobre su propia alimentación conforme a principios de sostenibilidad y seguridad) justifica la elección de alimentos elaborados en condiciones de proximidad geográfica, justicia social y respeto ambiental.

Estos alimentos cercanos, justos y naturales llegan al consumidor por dos itinerarios principales. Hasta los años $1990^{3}$ predominó la venta directa del productor al consumidor o al pequeño comercio especializado en un marco geográfico de proximidad que propiciaba la confianza entre los actores involucrados y minimizaba la distancia recorrida por los alimentos.

La expansión paulatina de este segmento del mercado atrajo la atención de los grandes operadores alimentarios y de las autoridades europeas. Dado que los primeros comenzaban a incluir en su catálogo alimentos bajo los reclamos mencionados, las segundas se vieron obligadas a regular los procedimientos de cultivo y transformación, los términos del empaquetado y el etiquetado mediante logotipos identificativos. En 1991, la Unión Europea aprobó su primer reglamento (CE 2092/91) sobre la agricultura y los alimentos ecológicos, seguida en 1999 por la incorporación de directrices semejantes al Codex Alimentarius de la FAO.

Esta entrada de los grandes supermercados en el mercado de alimentos ecológicos rompe el vínculo original de proximidad geográfica entre productores, distribuidores y consumidores. El abastecimiento a estos establecimientos exige importantes cantidades de producto y un complejo flujo de desplazamientos que compromete la sostenibilidad de la cadena de valor. De hecho, la normativa comunitaria de la Unión Europea ${ }^{4}$ no fija la distancia máxima que puede recorrer un alimento para ser vendido como ecológico. Por tanto, quienes abogan por la soberanía alimentaria, la sostenibilidad de la agricultura y el bienestar de sus trabajadores rechazan el término ecológico y prefieren el de agroecológico: los alimentos ecológicos y agroecológicos son idénticos desde un punto de vista agronómico, pero sólo la producción agroecológica contempla las implicaciones políticas, económicas y laborales de la alimentación.

Cahill y otros 2010 p.711

2 Vivas 2014

3 Willer y Yussefi 2000 p.54

4 Comisión Europea 2007 artículo 34 
El mercado de alimentos ecológicos en la Unión Europea presenta, pues, dos modelos de organización territorial ${ }^{5}$. El modelo corporativo, dominado por las economías de escala, es intensivo en distancia y poco sensible a los costes ambientales y sociales de la producción. El modelo agroecológico, de proximidad, conecta a consumidores y pequeños productores mediante sistemas autogestionados de abastecimiento que se corresponden -en la fase de distribución- con la centralidad que la agricultura familiar y campesina ocupa en el pensamiento y la práctica productiva de la agroecología 6 .

Este artículo se centra en el segundo modelo. Para ello, toma en consideración una de sus fórmulas organizativas más extendidas, los grupos de consumo. Estos grupos constituyen una alternativa agroecológica colectiva, minoritaria y localizada frente al poder creciente del modelo ecológico corporativo. Sin embargo, la imposibilidad efectiva de cubrir las necesidades de sus miembros con productos estrictamente agroecológicos lleva a algunos grupos a distribuir también alimentos con etiquetas ecológicas, pero que no se ajustan completamente a la filosofía de apoyo a producciones locales de pequeña escala que aspiran a construir la soberanía alimentaria. Por este motivo, en lugar de la expresión grupos de consumo agroecológico, muy extendida en la literatura ${ }^{7}$, este artículo los denomina grupos de consumo de alimentos ecológicos o, simplificando, grupos de consumo ecológico (GCE, en adelante), en línea con Barbeta ${ }^{8}$ o Argüelles y otros ${ }^{9}$ que estudian experiencias semejantes a las consideradas en este trabajo. El objetivo central del trabajo es la identificación de las distintas respuestas que están construyendo los GCE para responder al interés del modelo corporativo por la distribución de alimentos ecológicos.

Tras la revisión bibliográfica, se describe la estructura de la distribución de alimentos ecológicos en España, sujeta a una reestructuración derivada del esfuerzo de las grandes compañías por rentabilizar el crecimiento de la demanda. Se describe después la posición minoritaria, pero creciente, que ocupan los GCE como actores alternativos organizados en torno a la cercanía entre productores, distribuidores y consumidores. El objetivo central del trabajo es la identificación de las distintas respuestas que están construyendo los GCE para responder al peso creciente del modelo corporativo en la distribución de alimentos ecológicos. La base empírica procede del estudio en profundidad de tres GCE situados en el área metropolitana de Alicante. Las conclusiones recogen los aspectos más relevantes del estudio y sugieren líneas adicionales de investigación.

5 Goodman y Goodman 2009 p.2

6 Rosset y Altieri 2018

7 Vivas 2010, Méndez 2017, Varios Autores 2017

8 Barbeta 2014

9 Argüelles y otros 2017 


\section{La alimentación ecológica, entre la convencionalización y la construcción de las alternativas.}

La literatura sobre la alimentación ecológica puede dividirse en tres grandes corrientes que proponemos denominar militante, convencional y crítica.

La corriente militante ${ }^{10}$ está integrada por textos generados desde entidades del tercer sector que ponen el acento en tres aspectos. El primero es la crítica ambiental y social que cuestiona el impacto del orden alimentario dominante sobre los ecosistemas y la injusta distribución del valor generado en la cadena alimentaria. El segundo es la defensa de mecanismos alternativos de abastecimiento alimentario de carácter integral, es decir, que aspiran a resolver todas las deficiencias del modelo corporativo mediante la construcción de redes de productores y consumidores que comparten la convicción de que una alimentación natural, con producciones de pequeña escala, puede combatir la degradación del medio ambiente y construir un sistema socioeconómico comunitario y solidario. El tercero es la elaboración de guías de orientación para colectivos que deseen emprender iniciativas de este tipo.

La corriente convencional es de naturaleza académica y se sitúa en el extremo opuesto del abanico ideológico, porque describe los alimentos ecológicos como un mero segmento más del mercado ${ }^{11}$. Destacan dos temas de trabajo. Por un lado, la investigación sobre el perfil sociodemográfico de los consumidores de alimentos ecológicos: edad, nivel educativo, nivel de ingresos, actividad profesional, tamaño del hogar, estilo de vida, entre otros ${ }^{12}$. Por otro, la definición de los atributos que hacen atractivos a los alimentos ecológicos: etiquetado, empaquetado, ubicación en el supermercado, procedencia geográfica, proceso de elaboración, entre otros ${ }^{13}$. El punto de confluencia entre ambas perspectivas (de demanda y de oferta) se ubica en el vínculo entre alimentación, salud y sostenibilidad: los alimentos ecológicos se venden y se compran porque son más saludables y más respetuosos con la naturaleza, pero tanto los productos como los compradores aparecen desprovistos de cualquier voluntad de transformación social o política.

La corriente critica comparte con la militante la denuncia del modelo alimentario dominante, pero es de naturaleza académica, como la convencional. Una primera generación de investigaciones críticas se explica en el contexto de los escándalos alimentarios de las décadas de 1980 y 1990, sintetizados en Whitworth y otros ${ }^{14}$. Los alimentos ecológicos representaban una alternativa a los industriales, culpables de enfermedades y problemas de salud pública ${ }^{15}$.

La pequeña escala de la producción de alimentos ecológicos y su acceso al mercado a través de circuitos de proximidad y de establecimientos minoristas independientes sustentan una concepción de la calidad de los alimentos que se ampara en

10 MUNDUBAT 2012, Vivas 2010, López 2015, Suriñach 2017, Varios Autores 2017

11 Zanoli y otros 2012

12 Munuera y otros 2005, Fuentes y López 2008, Vega y otros 2011, Götze y otros 2016

13 Janssen y Hamm 2012, Thøgersen y otros 2017

14 Whitworth y otros 2017

15 Ilbery y Kneafsey 1998 
unos procesos de elaboración respetuosos con el producto y en el vínculo personal entre productores y consumidores ${ }^{16}$. Este proceso comenzó en los países donde el modelo industrial alcanzó mayor preponderancia, es decir, Estados Unidos, Australia, el Reino Unido, Escandinavia y Alemania, principalmente ${ }^{17}$.

Desde finales de la década de 1990, los grandes supermercados comienzan a distribuir alimentos ecológicos. Este proceso, que Guthman ${ }^{18}$ denomina convencionalización de la alimentación ecológica, implica la reducción de los valores originales a una simple cuestión nutricional (el contenido intrínseco de los alimentos), mientras los atributos extrínsecos (proximidad con el territorio y el productor) desaparecen de la definición de la calidad.

En torno a la noción de convencionalización aparece una segunda generación de textos críticos que plantean tres debates. Primero, el elitismo del nuevo consumidor ecológico perteneciente a clases medias o acomodadas, con alto nivel educativo y preocupado por su salud y la de su familia, que integra la alimentación ecológica en un estilo de vida caracterizado por el ejercicio físico regular y el contacto con la naturaleza. Segundo, la estandarización de la cadena ecológica de valor bajo la forma de certificaciones imprescindibles para concurrir en este mercado ${ }^{19}$. Lo que comenzó como una alternativa a la alimentación industrial se ha visto sometido a los mismos imperativos legales (tratamientos, envasado o etiquetado) de los que intentaba escapar, lo que provocará la desafección de los actores más comprometidos hacia estos eco-alimentos certificados por consultoras privadas. Tercero, como señalan Evans ${ }^{20} \mathrm{O}$ Alonso y otros ${ }^{21}$, el examen de las prácticas de aprovisionamiento en los hogares niega las visiones dicotómicas porque ni siquiera los consumidores más afines se surten exclusivamente de alimentos ecológicos, sino que los combinan con los convencionales en función de la disponibilidad, la comodidad o el precio.

El debate sobre la convencionalización coexiste en el tiempo con un tercer conjunto de trabajos que analiza la reacción del movimiento alimentario alternativo ante este proceso de cooptación ${ }^{22}$. Los alimentos ecológicos se entienden ahora como un elemento más del nuevo foodscape o paisaje alimentario que intenta reconstruir una alimentación local y saludable y al que pertenecen también los huertos urbanos, los mercados locales de productores, la agricultura respaldada por la comunidad o los grupos y cooperativas de consumo ${ }^{23}$.

Estas redes alimentarias alternativas ${ }^{24}$ mantienen una relación más matizada con los alimentos ecológicos. Algunas recuperan la visión política de los años 1980, rechazan los productos certificados por sus connotaciones capitalistas, y conceden

16 Buck y otros 1997 p.15

17 Parrott y otros 2002, p.242

18 Guthman 2004

19 Guthman 1998, Mutersbaugh y otros 2005, Rosin 2008

20 Evans 2011 p. 112

21 Alonso y otros 2014 p.35

22 Calvário y Kallis 2017 p.598

23 Maye y otros eds. 2007, Conill y otros 2012, Vivas 2014, Méndez y Monteserín 2017

24 Sánchez 2009 
prioridad a la proximidad geográfica, la confianza entre productor y consumidor y las prácticas agronómicas tradicionales ${ }^{25}$. Pero otras adoptan una organización para-empresarial, se especializan en alimentos respaldados por algún sello oficial, e intentan conectar con el consumidor a través de formatos de distribución cortos como las tiendas especializadas, el reparto a domicilio o las cooperativas de consumo ${ }^{26}$. En esta segunda variante, el cuidado de la salud a través de la dieta constituye el objetivo principal de los participantes y, sólo de forma colateral, se asume que esta opción individual tiene un efecto positivo, aunque indirecto, sobre el medio ambiente porque sustituye el consumo de alimentos convencionales por otros ecológicos.

La última línea argumental de esta literatura crítica cuestiona precisamente la deriva mercantilista, que aquí proponemos denominar neo-convencionalización, implícita en estas alternativas que apuestan por el alimento ecológico amparado por alguna marca privada o por un sello certificado. Son varios los autore ${ }^{27}$ que entienden que se trata de una solución neoliberal porque sustituye la acción colectiva por la individual (despojándose de toda aspiración a la transformación del sistema dominante) y confía en el mercado como palanca de transición hacia un modelo alimentario justo y sostenible. Para esta crítica con las tendencias en el mundo de la alimentación alternativa, es preocupante el aumento de participantes que buscan sobre todo un beneficio para su salud y la de su familia ${ }^{28}$ y relegan a un segundo plano la dimensión política y económica de la alimentación ecológica. En este punto, es imprescindible tener en cuenta la diferenciación que hacen Conill y otros ${ }^{29}$ en su estudio sobre las personas involucradas en las economías alternativas en la ciudad de Barcelona. Este trabajo distingue los practicantes alternativos o culturalmente transformadores (que buscan de manera activa y consciente la construcción de una sociedad no capitalista), los practicantes no capitalistas (que participan en estas prácticas, pero no les atribuyen un significado transformador) y los practicantes culturalmente adaptados (cuyas prácticas siguen mayoritariamente el modelo convencional).

Como propuesta de distribución alternativa, los GCE son herederos de las primeras reacciones contra la alimentación industrial y, hasta ahora, han permanecido al margen del proceso de convencionalización. Sin embargo, el aumento del número de iniciativas y del tamaño de algunas de ellas, por una parte, y la competencia creciente de la distribución organizada, por otra, los han colocado ante una serie de desafíos organizativos: surtido de productos, relación con los productores, vínculos entre los miembros, objetivos de la iniciativa... Los tres GCE que operan en el área metropolitana de Alicante representan otras tantas soluciones a tales retos, como se pondrá de manifiesto más adelante.

25 Alonso y otros 2014 p.24, Moragues 2017 p.467, Michelini y otros 2017 p.694

26 Barbeta 2014 p.84, Michelini y otros 2017 p.693, Grivins y otros 2017 p.345

27 Moragues 2017 p.459, Moragues y Marsden 2017 p.277 o Argüelles y otros 2017 p.32

28 Suriñach 2017 p.94

29 Conill y otros 2012 p.129 


\section{La distribución de alimentos ecológicos en España: el papel de los grupos de consumo. \\ Tendencias recientes en la comercialización de alimentos ecológicos}

La estructura de la distribución de alimentos ecológicos en España difiere notablemente de los países del centro y norte de Europa (Cuadro ${ }^{\circ} 1$ ) donde la convencionalización citada en el apartado anterior ha avanzado de manera evidente. El peso relativo del canal convencional es el más bajo, junto con Italia (38\%), de modo que los otros dos se reparten una cuota superior al $60 \%$. El MAGRAMA ${ }^{30}$ y el MAPAMA ${ }^{31}$ identifican, por tanto, un modelo mediterráneo de distribución de alimentos ecológicos que se diferencia del modelo anglosajón por el mayor peso del canal especialista (establecimientos donde todo o la mayoría de lo que vende es ecológico), mientras el canal convencional (establecimientos que sólo incluyen una sección de alimentos ecológicos) está dominado por la gran distribución ${ }^{32}$.

Cuadro 1. Estructura general del canal de distribución minorista de productos ecológicos en una selección de países europeos (2016) - porcentajes.

\begin{tabular}{lccc} 
País & Canal convencional $^{33}$ & Canal especialista $^{34}$ & Otros canales $^{35}$ \\
\hline España & 38 & 42 & 20 \\
Italia & 38 & 45 & 17 \\
Portugal & 45 & 51 & 4 \\
Francia & 44 & 39 & 19 \\
Alemania & 53 & 30 & 17 \\
Reino Unido & 67 & 3 & 30 \\
Suecia & 58 & 2 & 24 \\
Dinamarca & 74 & 2 & 40
\end{tabular}

Fuente: adaptado de MAGRAMA (2017b: 79)36

30 MAGRAMA, 2015 p.11

31 MAPAMA 2016 p.61

32 MAPAMA 2017a p.15

33 -Canal convencional: distribución organizada minorista, tiendas convencionales tradicionales, tiendas gourmet y delicatessen.

34 Canal especialista: tiendas ecológicas minoristas, herbolarios, grupos de consumo y similares. 35 Otros canales: venta directa, comercio electrónico, autoconsumo, restauración y hostelería. 36 Canal convencional: distribución organizada minorista, tiendas convencionales tradicionales, tiendas gourmet y delicatessen. Canal especialista: tiendas ecológicas minoristas, herbolarios, grupos de consumo y similares. Otros canales: venta directa, comercio electrónico, autoconsumo, restauración y hostelería. 
Esta concentración de las ventas en el canal especializado complica la obtención de economías de escala y, con ello, la reducción del diferencial de precios entre alimentos ecológicos y convencionales y la consiguiente generalización de su consumo. Además, la inferior presencia relativa de estos productos en la gran distribución dificulta su visualización en el acto de compra de los consumidores. De hecho, los altos precios y la baja disponibilidad de alimentos ecológicos en los canales convencionales son los principales argumentos esgrimidos por los consumidores para no optar por estos productos ${ }^{37}$.

Por tanto, los compradores ecológicos españoles tienen un perfil específico. La calidad del producto y la posibilidad de conocer al productor son, por encima del precio, los aspectos más apreciados por los clientes del canal especializado ${ }^{38}$, dato congruente con su preferencia por los alimentos locales y de proximidad ${ }^{39}$, muy por encima de consideraciones como la marca ${ }^{40}$. Ello se traduce en una alta fidelidad de la clientela hacia los establecimientos especializados: un 29\% de los consumidores de estos alimentos se abastece exclusivamente en este tipo de comercios $^{41}$.

La calidad intrínseca que estas personas atribuyen a los alimentos de proximidad repercutirá, en su opinión, en una mejora de su salud y la de sus familias, preocupación principal de los consumidores entrevistados por el MAPAMA ${ }^{42}$, que también reconocen practicar un estilo de vida saludable, hacer ejercicio, seguir una dieta mediterránea e incluso tender hacia el vegetarianismo. Lógicamente, los alimentos envasados son objeto de un cuidadoso escrutinio de las etiquetas que detallan su composición y se valora también que lleven sellos oficiales acreditativos de su condición ecológica. No obstante, un informe previo ${ }^{43}$ detecta que la certificación oficial parece menos importante que la proximidad y la confianza como criterios definitorios de la calidad; este debate, ya referido en la revisión bibliográfica, aparecerá en el estudio empírico posterior.

Los datos disponibles indican un crecimiento sostenido del consumo durante los años más recientes. Según el MAPAMA ${ }^{44}$, entre 2012 y 2016 el gasto en alimentación ecológica creció un $14 \%$ medio anual, pasando de 21,34 euros por habitante a 36,33 , mientras el gasto anual total en alimentación permaneció estancado en 2.151 euros. La cuota de participación del producto ecológico en la alimentación casi se duplicó en el período (de 0,99\% a 1,7\%). Este incremento de la demanda se ha traducido en un mayor valor de la producción en origen $(+12,06 \%$ en el intervalo citado) y en un aumento de las importaciones del 39,3\% anual entre 2012 y $2016^{45}$. En otro

37 MAGRAMA 2014 p.30

38 MAGRAMA 2013 p.98

39 MAGRAMA 2014 p.20

40 MAPAMA 2017a p.56

41 MAPAMA 2017a p.15

42 MAPAMA 2017a p.43

43 MAGRAMA 2013 p.98

44 MAPAMA 2017b pp.66-69

45 MAPAMA 2017b p.83 
informe ${ }^{46}$ se apreciaba un aumento del número de consumidores, de la frecuencia de consumo de estos alimentos, de su peso en el presupuesto doméstico y de la participación en canales alternativos, los grupos de consumo y la venta directa.

Estas tendencias no han pasado desapercibidas para la gran distribución. El $71 \%$ de los consumidores que no compra en el canal especializado opta por los hipermercados como punto de acceso a estos productos ${ }^{47}$. Gracias a la mayor superficie de venta de estos formatos, y a la consolidación del mercado ecológico en Francia, país de origen de dos de las cadenas de hipermercados más visitadas en España, estos formatos están impulsando con firmeza el proceso de convencionalización. Al fin y al cabo, son mayoría los consumidores que compatibilizan las compras en los canales especializado y convencional. Una eventual expansión de la oferta en este último, acompañada de una reducción de precios, trastocaría el actual modelo de distribución. El potencial de crecimiento es enorme si se advierte que, como señalaba la revisión bibliográfica, el consumidor habitual sólo compra en ecológico el 28\% de sus alimentos, y un $92 \%$ de ellos desearía incrementar esa cuota ${ }^{48}$.

La observación directa en el punto de venta demuestra que parte de la gran distribución en España (Lidl, Aldi, Carrefour, Alcampo, El Corte Inglés o Día) están apostando decididamente por el producto ecológico, habilitando secciones diferenciadas en sus establecimientos, incorporando opciones ecológicas en los lineales de productos o proponiendo una marca de distribuidor específica para estos alimentos. En consecuencia, la producción ecológica se está diversificando y ya no sólo procede de pequeños productores exclusivamente ecológicos, sino que otros convencionales de mayor dimensión empiezan a incorporar gamas ecológicas a su cartera comercial $^{49}$.

De ser un nicho de mercado pequeño, dominado por un canal especialista muy atomizado, la alimentación ecológica avanza hacia la convencionalización de la mano de la gran distribución comercial, como ha sucedido ya en Alemania, Escandinavia o Francia. Según el MAPAMA ${ }^{50}$, se está reduciendo el número de unidades comerciales, fundamentalmente de pequeños comercios y herbolarios independientes, mientras los supermercados con dedicación en exclusiva al producto ecológico se expanden formando cadenas de ámbito regional o bajo la fórmula de la franquicia. Estos cambios sugieren que la convencionalización del mercado de alimentos ecológicos en España no se limita a la expansión de la cuota de mercado de la gran distribución comercial y a la entrada de grandes procesadores en la fase de producción y transformación de los productos frescos, a fin de abastecer a un número mayor de puntos de venta. El propio canal especialista está sufriendo lo que más arriba hemos denominado neo-convencionalización, donde las tiendas pequeñas e independientes ceden terreno ante nuevas empresas de distribución ecológica que

46 MAGRAMA 2014 p.48

47 MAPAMA 2017a p.16

48 MAGRAMA 2014 p.31

49 MAPAMA 2016 p.61

50 MAPAMA 2015 p.79 
reproducen el modelo convencional de gestión basado en la búsqueda de economías de escala para reducir los precios y aumentar la cuota de mercado.

\section{Los grupos de consumo en el mercado ecológico español}

Según Vivas"1, los grupos de consumo ecológico son "colectivos que agrupan gente de un mismo territorio con objeto de llevar a cabo un consumo alternativo, ecológico, solidario con el mundo rural, relocalizando la alimentación y estableciendo unas relaciones directas entre el consumidor y el productor, a partir de unos circuitos cortos de comercialización". Están formados por personas que se organizan de forma autónoma para adquirir productos (agro)ecológicos de alimentación, pero también de cosmética, limpieza e incluso, equipamiento personal. Habilitan un canal comercial muy corto donde obtienen alimentos de procedencia local o regional de productores que apoyan los principios de la soberanía alimentaria. La proximidad geográfica reduce el impacto ambiental del transporte y permite precios finales más justos para los productores, al suprimir los intermediarios. Es, por tanto, un modelo que conecta los extremos de la cadena de valor y protege sus intereses respectivos, y no solamente los de fabricantes y distribuidores.

Los integrantes de los GCE rechazan las jerarquías, toman las decisiones en asambleas o grupos de trabajo y asumen voluntariamente toda la labor organizativa interna: contacto con los productores, tramitación de los pedidos semanales, contabilidad, limpieza, selección de los nuevos proveedores, formación de los socios, recogida semanal o quincenal de los pedidos, trabajo voluntario, compromiso personal con el grupo y solidaridad entre los miembros (y de éstos con los productores) son los principios fundamentales de los GCE.

Los GCE son un fenómeno relativamente nuevo en España. Según Vivas ${ }^{52}$, el primero surgió en 1987 en Reus (Barcelona); a lo largo de la década de 1990, el impulso procedía de los productores, articulados en la Plataforma Rural y los foros Por un mundo rural vivo, que conciben los GCE como un medio para vincular consumidores urbanos y comunidades rurales en torno a la búsqueda de la soberanía alimentaria $^{53}$. Una segunda etapa de expansión, en los años 2000, se genera en el ámbito urbano, en el entorno de los movimientos antiglobalización y del comercio justo. La tercera fase tiene también raíces urbanas, en este caso vinculadas a las protestas de los indignados que ocuparon las plazas de muchas ciudades españolas en mayo de 2011 y promovieron en años posteriores la constitución de GCE, mercados de productores o huertos urbanos autogestionados ${ }^{54}$.

El MAPAMA ${ }^{55}$ contabiliza los GCE en el canal especialista y sumarían en torno al 14\% del mercado ecológico español. Es una cifra baja en términos cuantitativos, pero resulta significativa porque que se refiere a un modelo de organización cons-

51 Vivas 2010 p.54

52 Vivas 2014 p.185

53 López 2011

54 Pascual y Guerra 2019

55 MAPAMA $2017 \mathrm{~b}$ p. 80 
truido a partir del activismo, con escasos recursos materiales y que propone una alternativa al sistema agroalimentario capitalista. Los GCE participan de una solución espacial del mercado ecológico marcada hasta fechas muy recientes por la fragmentación geográfica de la demanda, agrupada en pequeños nichos de mercado en cada ciudad.

En esta solución, los GCE han cumplido dos funciones básicas: establecer relaciones comerciales estables, de confianza y de proximidad con productores ecológicos, excluidos inevitablemente de la gran distribución comercial, y ampliar el número de puntos de aprovisionamiento ecológico para los miembros. Además, la gestión de los GCE no sólo garantiza el suministro de productos (agro)ecológicos, sino que evalúa todas las fases de la cadena de valor para asegurar su coherencia con el modelo defendido. De hecho, muchos de estos GCE trascienden el objetivo de venta y aprovisionamiento de alimentos para crear "un movimiento social que cuestione la expresión territorial de la globalización capitalista y construya alternativas mediante relaciones económicas entre producción y consumo basadas en la solidaridad y el bien común"56.

En la actualidad, las fórmulas organizativas de los GCE muestran una heterogeneidad considerable que depende de la fase del ciclo de vida en que se encuentre cada uno, de la forma jurídica que adopte con el tiempo (agrupación informal, asociación formalizada, cooperativa de consumo) y de la posibilidad de que personas no socias participen en la gestión interna y la compra de productos ${ }^{57}$. También hay que mencionar el apoyo que puedan recibir los GCE de otras experiencias locales de economía alternativa ${ }^{58} \mathrm{o}$ incluso de la administración pública en las ciudades que están implantando estrategias de alimentación sostenible y agroecológica ${ }^{59}$. Todo ello, en el fondo, viene condicionado por las expectativas de evolución a medio y largo plazo que tengan sus componentes, bien hacia la conservación de la filosofía comunitaria original, bien hacia la incorporación de mecanismos de gestión más empresarial que maximicen la utilidad de sus integrantes.

En este sentido, una investigación reciente a escala española ${ }^{60}$ demuestra que algunos GCE se autoimponen un límite de unidades de consumo, pero también hay otros que aspiran a construir una alternativa efectiva a la distribución convencional, por lo que el crecimiento y las economías de escala son fundamentales. Así, mientras los GCE pequeños trabajan en locales cedidos por otras asociaciones u organismos públicos, los grupos más estables y orientados al crecimiento lo hacen con locales propios o en alquiler para aumentar su volumen de actividad. Por tanto, algunos GCE conservan su planteamiento agroecológico original, abasteciéndose únicamente de productores locales a los que se les exige unos requisitos de situación laboral regulada, con certificado de confianza o sello ecológico (según el

56 Sanz y otros 2017 p.48

57 Michelini y otros 2017

58 Pascual y otros 2018

59 López y otros 2018, Sánchez y Pitarch 2019

60 Espinosa, 2019 
acuerdo de la asamblea del grupo). Pero otros GCE evolucionan hacia soluciones menos dependientes del voluntariado y adoptan una gestión más profesionalizada, con trabajadores asalariados o llegando, en ocasiones, a constituir asociaciones de consumidores y cooperativas de consumo. En estos casos, los GCE distribuyen un amplio surtido de productos. A los alimentos agroecológicos de proximidad se les añaden otros artículos importados o elaborados por grandes empresas ecológicas, con el propósito final de satisfacer todas las necesidades de sus miembros. Evidentemente, la composición inicial de cada GCE y la trayectoria vital de sus integrantes terminarán por condicionar su evolución en el tiempo.

Por tanto, el comportamiento reciente de los GCE manifiesta indicios de esa neo-convencionalización que también ha sido detectada por el MAGRAMA ${ }^{61}$ cuando afirma que los GCE "han crecido en organización y capacidad de oferta de productos a sus asociados, constituyéndose en algunos casos como verdaderas organizaciones de compra centralizadas, no sólo de productos frescos sino también de productos envasados, lo que ha aumentado su atractivo de cara a la satisfacción de las necesidades de compra del cliente" 62 .

El estudio de caso en Alicante indaga en el origen de los GCE en esta ciudad, el perfil de sus socios, su organización interna y su reacción ante los cambios recientes en el sector, donde se verá reflejada esta tensión entre la fidelidad a los planteamientos comunitarios y políticos originales y la adopción de prácticas de gestión más empresariales, que corre paralela a la transformación del perfil de los miembros de estas iniciativas.

\section{Los grupos de consumo de alimentos ecológicos del área metropoli- tana de Alicante. \\ Metodología y fuentes de información}

A fin de comprender el papel que poseen actualmente los GCE en la distribución de alimentos ecológicos y la influencia que los cambios descritos en la distribución de estos productos están ejerciendo sobre su funcionamiento interno, se proponen las siguientes preguntas de investigación: 1.) ¿Qué factores explican la formación de los GCE en Alicante? 2.) ¿Qué agentes participan en estas experiencias y qué objetivos persiguen con su participación? 3.) ¿Cómo ha evolucionado su funcionamiento?; ¿continúan representando una alternativa al modelo alimentario convencional o se observan indicios de neo-convencionalización como consecuencia de la expansión del consumo de alimentos ecológicos?

Para contestar estas preguntas con respaldo empírico suficiente, se han seleccionado los tres únicos GCE activos en la ciudad de Alicante: Bioalacant, Mercatrèmol y Biotrèmol. En la fecha de realización de este estudio, en la provincia de Alicante están operando productores agroecológicos independientes y cooperativas de productores que realizan un abastecimiento informal y semanal productos agroecológicos a

61 MAGRAMA 2015 p.13

62 MAGRAMA 2015 p.15 
domicilio, pero que también proveen a los tres grupos de consumo en los que se ha centrado este estudio.

Los gerentes de dichos grupos de consumo fueron entrevistados en junio de 2016 para conocer el origen y evolución del grupo, los procedimientos de gestión interna y los criterios de selección de los productores y distribuidores de los alimentos que ofrecen a los miembros. Las entrevistas fueron grabadas y transcritas y su duración media fue de 45 minutos. Después han sido tratadas con el software $N$-Vivo 11 para codificar su contenido e identificar los argumentos principales.

Además, se diseñó un cuestionario en línea para los miembros o socios de estos GCE, que fue distribuido a través de correo electrónico por los responsables de cada iniciativa entre marzo y mayo de 2017. La opción por el cuestionario en línea frente al tradicional formulario en papel fue sugerida por los gerentes de los tres GCE, que coincidieron en considerar que de esta forma se lograría un mayor número de respuestas, puesto que los miembros están habituados al uso del correo electrónico como herramienta interna de gestión de los GCE (pedidos, noticias de agroecología o de los propios grupos de consumo o distribución de tareas). La información recabada por este medio no debería estar sujeta, pues, a ningún sesgo específico capaz de distorsionar los resultados de la investigación, salvo el caso de las personas consumidoras no socias de Biotrèmol, muchas de ellas ocasionales que no están representadas porque la gerencia del grupo no dispone de sus datos de contacto. Además, el acceso a Internet a través del teléfono móvil permite cumplimentar este tipo de cuestionarios incluso a personas que carecen de conexión doméstica.

Este cuestionario consta de 31 preguntas que abarcan los siguientes temas: perfil sociodemográfico, hábitos de consumo, motivos de participación en el GCE y grado de activismo social, político y ambiental. El cuestionario fue remitido a los 703 socios de los tres GCE. Se obtuvieron 181 respuestas, el 25,74\% del universo estadístico, de forma que, para un nivel de confianza del 95\%, se obtiene un margen de error de $+/-6,5 \%$. Los resultados son significativos para conocer los rasgos fundamentales de los participantes en los GCE dentro de un área metropolitana española de tamaño medio como es Alicante (465.782 habitantes en 2018, última cifra oficial para dicha escala, de los que 331.577 corresponden a la ciudad central).

\section{El origen de los grupos de consumo de alimentos ecológicos en Alicante.}

El área metropolitana de Alicante cuenta con tres organizaciones de consumo ecológico (Cuadro $\mathrm{n}^{\mathrm{0}} 2$ ), dos de ellas registradas como asociaciones de consumidores (Bioalacant, fundado en 1998, y Mercatrèmol, que data de 2008) y una tercera constituida como cooperativa de consumo en 2015 (Biotrèmol). Los dos primeros nacieron por iniciativa de colectivos reducidos de personas que querían autogestionar el abastecimiento de productos ecológicos para consumo propio al margen de la gran distribución comercial. El tercer caso fue impulsado por miembros de Mercatrèmol, y constituye un proyecto más expansivo y abierto que representa el comienzo del proceso de neo-convencionalización en el mundo ecológico alternativo de Alican- 
te. Este número de casos es muy bajo en relación con la población de Alicante y su entorno inmediato, si se lo compara con otras ciudades españolas de tamaño semejante donde han proliferado las experiencias alimentarias alternativas desde el año $2008^{63}$.

El ejemplo más antiguo es Bioalacant, que fue promovido desde una granja de producción agroecológica del municipio de Alicante: “Abrimos en 1998 y nuestros objetivos eran los mismos que ahora. Cuando empezamos es porque estábamos plantando en la huerta y a pesar de que teníamos mucha variedad de huerta, no era suficiente para consumirlo todo ecológico (...) Y acabamos montando la tienda, porque teníamos contactos de toda la vida y la verdad que no era tan difícil".

Las otras dos experiencias provienen de un huerto comunitario para autoconsumo ( Terratrèmol) iniciado en el año 2005 y gestionado por una docena de familias como un acto de resistencia frente al avance de la edificación residencial. Así nació Mercatrèmol en 2008 para ampliar la limitada gama de alimentos que proporciona la huerta y formar "...una estructura que permitiera abastecer a las familias de todo lo necesario para el día el día, en cuanto a alimentación se refiere", es decir, el mismo motivo que empujó a Bioalacant a fundar su GCE: crear una oferta estable para una demanda insatisfecha con el mercado de productos agroecológicos.

Biotrèmol se escindió de Mercatrèmol en 2015: "Cuando nosotros nos vinimos aquí, vimos que había que mejorar el proyecto de Mercatrèmol. (...) Unos querían ser un proyecto más familiar, que no se nos fuera de las manos y otros queríamos ser una alternativa de consumo y hacer una propuesta de consumo a la sociedad. Por lo que necesitábamos crecer, para abaratar el producto y mover mucha más cantidad. Entonces es cuando hubo una escisión amistosa".

Por tanto, los orígenes de estas experiencias guardan relación con la evolución del movimiento del consumo de alimentos ecológicos que describe la literatura y con los factores definidos por Vivas ${ }^{64}$ para el caso español: iniciativa de los productores en los años 1990 y de los movimientos críticos urbanos en los años 2000. Es muy probable que el pequeño número de prácticas alternativas de producción, consumo e intercambio en Alicante ${ }^{65} \mathrm{y}$ el nulo apoyo a las mismas por parte del Ayuntamiento ${ }^{66}$ hayan contribuido a concentrar los esfuerzos de los escasos participantes culturalmente transformadores ${ }^{67}$ en el sostenimiento de estos tres GCE que, por otra parte, también admiten dificultades para aumentar su número de miembros.

\section{Perfil sociodemográfico y objetivos de los grupos de consumo de alimentos eco- lógicos en Alicante}

Los tres GCE tienen un reducido número de miembros, si bien la expansión de Biotrèmol se ha traducido ya en la apertura de cuatro tiendas -tres de ellas localiza-

63 González y Torres 2019

64 Vivas 2014 p. 187

65 González y Torres 2019

66 Sánchez y Pitarch 2019

67 Conill y otros 2012 
das fuera del área de estudio y, por tanto, no consideradas en esta investigación- y una mayor base social (Cuadro $\mathrm{n}^{0} 2$ ). Mercatrèmol y Biotrèmol cuentan también con socios especiales formados por grupos de consumo muy pequeños localizados en pueblos de otras comarcas; estos grupos compran directamente a estos dos GCE de mayores dimensiones para abastecer a varias familias, aunque son casos muy aislados y no participaron en este análisis.

Cuadro 2. Datos básicos de los grupos de consumo de Alicante (2016)

Biotrèmol

Año de inicio

1998

2008

2015

Número de socios

57

175

$471 *$

Cuota de los socios

Mecanismo de Horas de apertura
semanal

Incremento del precio en origen (coste del producto a la organización) público no socio

Admite pago con tarjeta financiación

Admite venta al

$35 €$ anual $\quad 10 €$ mensuales

Cuotas de socios y coste del producto

al grupo de consumo

18 horas (2 días)

$35 \%(40 \%$ a los productos perecederos)

No

No

Cuota mensual de los socios y coste del producto a la asociación

28 horas ( 5 días)

$12 \%$

$15 \%$

Sí

Fuente: elaboración propia a partir de las entrevistas ${ }^{68}$

Los resultados del cuestionario detallan el perfil de los miembros de estos GCE (Cuadro $n^{\circ} 3$ ). Son personas de mediana edad (44,7 años) y, al menos entre quienes respondieron, de sexo femenino en su mayoría $(69,1 \%$ ), lo que puede estar relacionado con la pervivencia de roles diferenciados entre hombres y mujeres sobre las decisiones de alimentación y la tarea de hacer las compras. El 82,3\% tienen títulos universitarios o de doctorado, es decir, un alto nivel educativo que la literatura relaciona con este perfil de consumidores, concienciados sobre las implicaciones del sistema alimentario convencional y la existencia de alternativas ecológicas.

El 75\% conocieron su GCE a través de amigos y familiares y participan en esta actividad desde hace cinco años en promedio, con las variaciones lógicas derivadas

68 El estudio se realizó exclusivamente en la tienda de la cooperativa localizada en la ciudad de San Vicente del Raspeig, muy próxima a la Universidad de Alicante. 


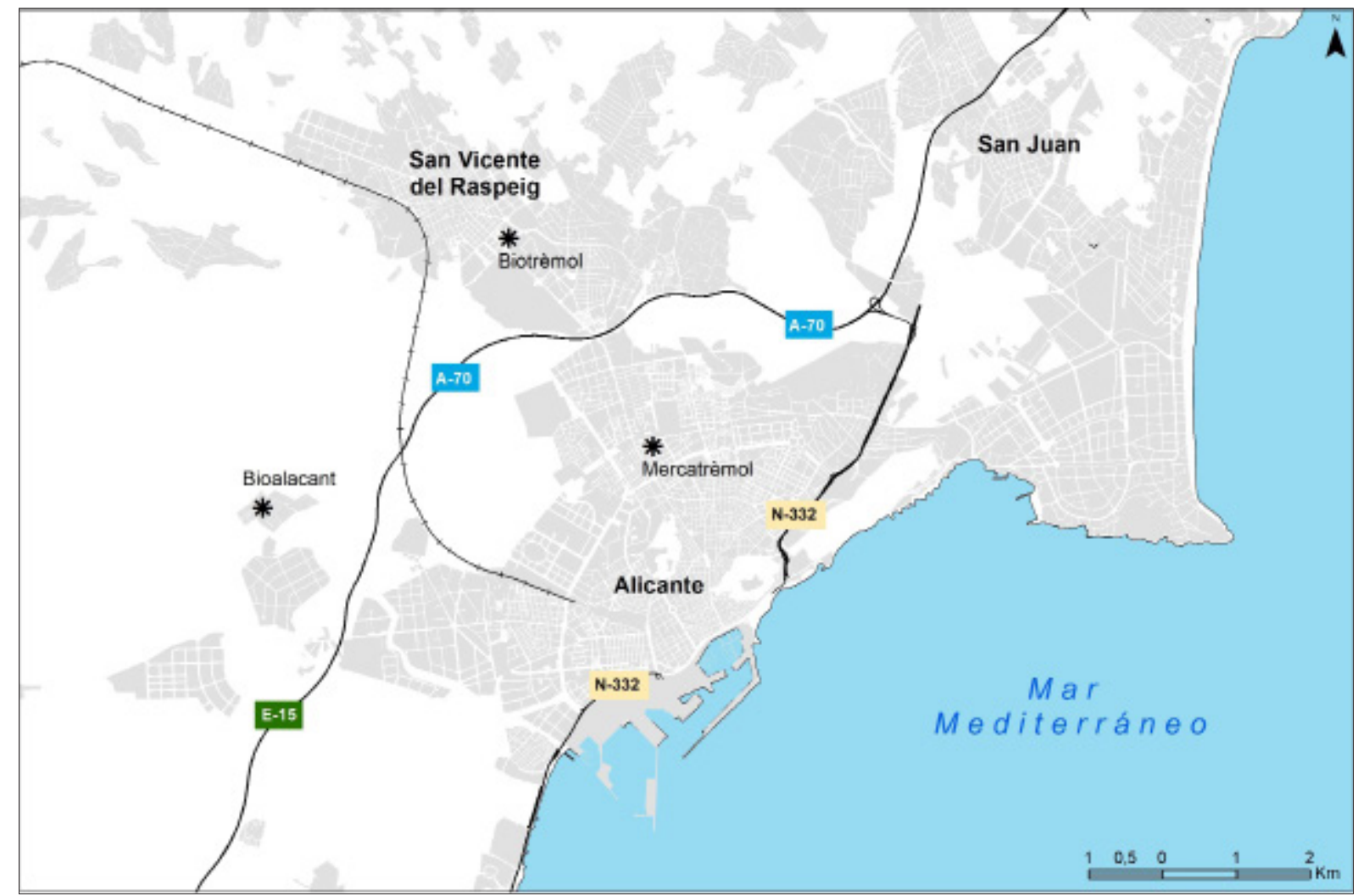

Figura 1. Localización de los grupos de consumo de alimentos ecológicos en Alicante.

Fuente: Elaboración propia.

de la distinta antigüedad de cada caso. El 95\%, además, señala que la compra está destinada a todos los miembros de la unidad familiar y no sólo a niños o enfermos. Se refleja aquí de manera evidente la tendencia social hacia estilos de vida más sostenibles y saludables.

Cuadro 3. Perfil de los miembros de los grupos de consumo ecológico de Alicante

\begin{tabular}{|c|c|c|c|c|}
\hline Variable & Bioalacant & Mercatrèmol & Biotrèmol & Total \\
\hline Edad media (años) & 48,5 & 46,9 & 41,2 & 44,7 \\
\hline$\%$ mujeres & 73,9 & 65,9 & 71,1 & 69,1 \\
\hline $\begin{array}{l}\text { Miembros con estudios } \\
\text { universitarios o de doctorado (\%) }\end{array}$ & 78,3 & 79,3 & 86,8 & 82,3 \\
\hline Fecha promedio de adhesión & 2008 & 2013 & 2015 & 2013 \\
\hline Nunca me he dado de baja (\%) & 100,0 & 84,1 & 85,5 & 86,7 \\
\hline $\begin{array}{l}\text { Conocí el GCE a través de amigos y } \\
\text { familiares (\%) }\end{array}$ & 95,7 & 86,6 & 56,6 & 75,1 \\
\hline
\end{tabular}


Distancia a la tienda (km.)

Uso el automóvil para desplazarme al GCE (\%)

Importe medio de cada compra $(€)$
8,5

100,0

324
4,7

70,7

172
5,2

56,6

166
5,4

68,5

189

Fuente: elaboración propia a partir de los resultados del cuestionario en línea (2017).

En general, residen en un radio de 5,4 kilómetros del punto de recogida de los pedidos, distancia que supera de largo la habitual en España entre los establecimientos de distribución minorista convencional de alimentos y el domicilio de los consumidores. Esto tiene dos implicaciones: una, la alta fidelidad al GCE ( sólo el 13,3\% reconoce haberse dado de baja durante algún tiempo) y dos, el uso del automóvil particular (encarnación de la movilidad urbana insostenible) por parte del $68 \%$ de los clientes para llegar al punto de venta. La escasez de grupos de consumo ecológicos en Alicante obliga a los socios/as a cubrir distancias largas con el fin de abastecerse de los productos que requieren.

Los puntos de distribución de estos GCE no tienen una localización intencionada (Figura 1) y su ubicación no obedece a la concentración en su barrio de los practicantes culturalmente transformadores o alternativos que definen Conill y otros ${ }^{69}$. Al contrario, los miembros de los GCE acuden al proyecto que más confianza les ofrece, pero no por comodidad o cercanía, sino más bien por cautividad de su consumo. Parece entonces que los GCE de Alicante no responden a ninguna de las estrategias de localización que busca la distribución convencional (centralidad, accesibilidad o cercanía a la demanda), ni tampoco a la búsqueda de entornos urbanos progresistas bien conectados social, digital y territorialmente con los actores de producción y distribución, como se ha constatado en los GCE de otras ciudades españolas como Madrid $^{70}$, Valladolid o Salamanca ${ }^{71}$.

Si a este patrón de localización de los puntos de venta se le suman las restricciones en el horario de atención al público, se entiende mejor que un 86\% admita comprar alimentos en otros establecimientos más cercanos y con oferta convencional, y que sólo el 12,7\% compre en su GCE más de una vez a la semana, siendo las frecuencias más habituales de compra la semanal (58\%) y la quincenal (19,9\%).

Es decir, el consumo en el GCE no es exclusivo y se complementa con otras fuentes de abastecimiento más cómodas o cercanas, porque un 60\% de los encuestados reconocía que dejarían su actual GCE si abrieran otro más próximo a su domicilio. En las entrevistas, caso de Mercatrèmol, este factor fue citado como causa habitual de los abandonos registrados: "De hecho, mucha gente se da de baja porque no acaba de integrarlo en su rutina, no quiere coger el coche, pasan dos semanas y no ha venido, está pagando una cuota y no la usa y cuesta mucho...".

La cesta de productos adquiridos refleja las características del mercado español de alimentos ecológicos (Cuadro $\mathrm{n}^{\mathrm{0}} 4$ ). Los productos vegetales son ampliamente 
demandados (frutas y verduras frescas y productos a granel), mientras los de origen animal (carnes, pescados, leche) tienen una clientela más reducida, que obliga a una venta por encargo para minimizar mermas en las tiendas. Los productos elaborados (refrigerados, limpieza, cuidado personal, pan y similares) tienen menor presencia, quizás porque los GCE tampoco puedan ofrecer un surtido suficiente o asequible a los socios.

Cuadro $n^{\circ} 4$. Tipos de productos distribuidos en los grupos de consumo de Alicante.

Productos

$\%$ de socios que mencionan su compra

Productos frescos: fruta y verdura

Productos envasados

Productos a granel

Productos para el hogar

Productos para el cuidado personal

Productos frescos: carne y pescado

Refrigerados y lácteos

Pan, bollería y dulces
98,9

85,6

80,1

56,9

47,5

32,0

3,3

Fuente: elaboración propia a partir de los resultados del cuestionario en línea (2017).

Según las entrevistas, los GCE persiguen tres objetivos. Primero, crear un espacio económico alternativo que concentre la oferta y demanda de alimentos ecológicos. Se trataría de proporcionar a los productores un canal de venta estable y de facilitar a los consumidores el acceso a los alimentos en un único lugar, evitando así la tarea de buscarlos en establecimientos diferentes: "El [objetivo] económico no era tanto rentabilizar la producción, porque esto es una asociación sin ánimo de lucro, sino que hubiera un sitio donde ir... Era centralizar el espacio de venta. Luego fuimos trayendo otro tipo de productos más trasformados. En los fines de la asociación es que haya un poco de todo para que no acabes yendo a comprar a supermercados, a la gran superficie. Queremos que haya de todo para que el que quiera, que no necesite ir a ningún sitio" (Bioalacant). Constituir una alternativa real de consumo frente a la gran distribución es un objetivo irrenunciable de los tres GCE y, de hecho, un 13\% de los encuestados afirmó realizar todas sus compras en su GCE. A pesar de ello, la mayoría de los encuestados afirman que es muy complicado abastecerse en 
exclusiva desde el GCE y por el momento, complementan sus compras en establecimientos convencionales, en mercadillos ambulantes o en tiendas especializadas en productos ecológicos.

Es también destacable que las tres organizaciones, a pesar de apostar por la soberanía alimentaria y la agroecología, reconozcan que amplían su surtido e incluyen productos que no cumplen completamente con sus criterios de selección, con el fin de convertirse en una propuesta económica efectiva: "Nosotros intentamos favorecer las economías familiares y pequeñas, pero cuando no podemos, tenemos empresas que son realmente grandes. Queremos tener de todo para que realmente seamos una alternativa de consumo y que hagan la compra aquí" (Biotrèmol).

El segundo objetivo aspira a convertir estos espacios en instrumentos de transformación social, económica y ambiental: “apoyar las pequeñas producciones locales, de manera que creemos una economía más redistributiva, evitar el deterioro de suelo, agua a consecuencia del consumo de pesticidas y químicos que se utilizan, defensa del derecho a la salud a través de la alimentación y al final todo esto se resume en temas de soberanía alimentaria, agroecología y colaboración entre consumidores y productores" (Mercatrèmol). De hecho, los tres GCE apoyan distintivos de confianza ecológicos propios para los productores ecológicos locales que no se plantean inscribir su producción ecológica en los comités de agricultura ecológica regionales. En proyectos de agricultura familiar de pequeñas dimensiones, la certificación ecológica encarece mucho el producto y el proceso de producción. Por ese motivo, hay agricultores ecológicos que consideran que la certificación ecológica beneficia a la agricultura de mercado y no a la agricultura de proximidad. Se niegan a equipararse con agroempresas que no cumplen con criterios de sostenibilidad social y laboral de sus empleados y de sostenibilidad ambiental, por dedicar la mayoría de su producción a monocultivos preparados para la exportación, con los costes externos de envasado, transporte y mantenimiento que ello conlleva.

El Cuadro no 5 refleja las dimensiones del constructo "consumidor responsable" de manera cuantitativa: aplicando una escala Likert ( siendo 1 el valor más bajo y 5 el valor más alto), se preguntó a los encuestados por su conformidad con una serie de afirmaciones referidas a las prácticas de consumo responsable en su participación en los GCE y en sus hábitos diarios.

La puntuación media para el total de la muestra (columna derecha del Cuadro) supera el 4 en casi todas las afirmaciones, salvo las dos últimas, que intentan capturar el grado de compromiso o activismo político. 
Cuadro 5. Dimensiones del constructo Consumidores responsables en los GCE de Alicante ${ }^{72}$.

\section{Consumidores/as responsables con su salud}

1. Estoy preocupado/a por lo que como

2. Me fijo mucho en lo que compro y leo las etiquetas muy bien

3. Leo y me informo sobre alimentación sana
4,8

4,7

4,6
4,6

4,1

4,2
4,6

4,6

Consumidores/as responsables con su entorno social, económico y medioambiental

4. Prefiero consumir productos locales,
4,7

4,5

4,9

4,9

4,6

4,7

4,4 cultivados o elaborados cerca de donde vivo

5. Me fijo mucho dónde compro

6. Me preocupa saber de dónde vienen los productos que compro

7. Estoy dispuesto a pagar más por productos respetuosos con el medio ambiente y la sociedad

8. Reciclo todo lo que puedo y reutilizo todo lo posible

9. Intento apoyar a los pequeños productores

10. Intento apoyar al pequeño comercio

4,6

4

4,3

4,4

4,4

4,5

4,2

4,4

\section{Consumidores/as activistas con su consumo}

11. Quiero ser un activista social, político o medioambiental con mi consumo

3,6

3,8

3,8

12. Utilizo mi consumo como una herramienta política

4

3,2

3,3

Destaca la relevancia asignada a las afirmaciones relacionadas con la calidad y procedencia de los alimentos consumidos $\left(\mathrm{n}^{0} 1,4\right.$ y 6$)$ y con el apoyo a los productores pequeños ( $\left.\mathrm{n}^{0} 9\right)$; como el resto de consumidores ecológicos en España, están dispuestos a pagar más por alimentos obtenidos de manera justa y sostenible ( $\left.\mathrm{n}^{\circ} 7\right)$. También se ofreció a los encuestados la posibilidad de seleccionar, entre una serie de afirmaciones, aquélla con la que se sintieran más identificados (Cuadro ${ }^{\circ} 6$ 6). Primero, queda comprobado que no se acude a estos puntos de venta por comodi-

72 Media aritmética de las puntuaciones asignadas por los encuestados a cada una de las afirmaciones (1: nada de acuerdo - 5: totalmente de acuerdo). 
dad, proximidad o surtido. Segundo, la salud personal y familiar es el motivo más frecuente (54,7\% de los participantes), seguido de lejos por el compromiso con la transformación social (19,3\%) y la producción local (16\%).

Cuadro 6. Respuestas a la pregunta "¿Con cuál de estas afirmaciones te sientes más identificado?"

\begin{tabular}{|c|c|c|c|c|c|}
\hline Afirmaciones & Bioalacant & Mercatrèmol & Biotrèmol & Total & Total \% \\
\hline $\begin{array}{l}\text { Compro aquí por comodidad y } \\
\text { cercanía a mi trabajo y/o casa }\end{array}$ & 0 & 0 & 0 & 0 & 0 \\
\hline $\begin{array}{l}\text { Compro aquí porque la oferta } \\
\text { de productos ecológicos } \\
\text { es la más completa que he } \\
\text { encontrado }\end{array}$ & 1 & 7 & 7 & 15 & 8,3 \\
\hline $\begin{array}{l}\text { Compro aquí porque me } \\
\text { preocupa la salud, lo que como } \\
\text { y lo que come mi familia }\end{array}$ & 13 & 39 & 47 & 99 & 54,7 \\
\hline $\begin{array}{l}\text { Compro aquí porque sé que } \\
\text { ayudo a los productores a } \\
\text { vivir mejor y a mejorar mi } \\
\text { comunidad }\end{array}$ & 3 & 16 & 10 & 29 & 16,0 \\
\hline $\begin{array}{l}\text { Compro aquí porque soy } \\
\text { un/a activista (social, } \\
\text { medioambiental o político) }\end{array}$ & 6 & 19 & 10 & 35 & 19,3 \\
\hline Todas ellas & 0 & 1 & 2 & 3 & 1,7 \\
\hline Total general & 23 & 82 & 76 & 181 & 100,0 \\
\hline
\end{tabular}

El objetivo transformador original convive hoy día con la búsqueda de una alimentación más sana, como señalaba la corriente más actual de la literatura crítica y ratifica la entrevista con Biotrèmol: "Hace 4-5 años, cuando estábamos en Mercatrè$m o l$, hice un estudio sobre qué tipo de socio entraba en la asociación... Un tercio de nuestros socios eran gente concienciada políticamente sobre la alimentación. Otro tercio era gente que venía con "receta médica" por problemas de salud... Y el otro tercio venía de gente que estaba en proyectos de desarrollo personal... Este año he vuelto a hacer el estudio aquí ya en Biotrèmol... El bloque de la conciencia política ha bajado hasta quedarse casi inexistente... El bloque de desarrollo personal se ha mantenido... El tema de problemas de salud se ha disparado. La mayoría de gente que entra aquí es para prevenir problemas de salud. Y sobre todo parejas jóvenes con niños, para proteger a los niños".

Podría argumentarse, a la vista de estos datos, que los GCE se estén convirtiendo en una opción complementaria de abastecimiento de productos ecológicos para consumidores que no poseen un perfil activista, sobre todo en ciudades medias 
como Alicante donde la oferta en tiendas convencionales es limitada. Es decir, las limitaciones estructurales del mercado ecológico español han obligado a los consumidores interesados por la salud o el medio ambiente a involucrarse en los GCE para ampliar su consumo de estos productos. Recurriendo de nuevo a la tipología de Conill ${ }^{73}$, en los GCE de Alicante están ganando presencia los practicantes culturalmente adaptados. Lo inesperado es que una vez que han integrado los GCE en sus rutinas, estos participantes mantienen su fidelidad a estos mecanismos de consumo y los prefieren a los puntos de venta de la gran distribución comercial. Así lo indican las respuestas a la pregunta “ ¿Te has dado de baja en algún momento?", a la que respondieron negativamente todos los socios de Bioalacant, el 17\% de los de Mercatrèmol y el 19\% de los de Biotrèmol.

El tercer objetivo de los GCE consiste en articular mecanismos organizativos capaces de extender socialmente y difundir geográficamente la alimentación agroecológica. Justamente en este punto se va a producir la división entre las propuestas fieles a los planteamientos originales de autogestión comunitaria y las propuestas más empresariales que se adentran en la senda de la neo-convencionalización. Las primeras apuestan por la proliferación de GCE independientes en distintos barrios de la ciudad: “¿Abrir otro? Claro que nos encantaría, pero me gustaría más que no fuera un Mercatrèmol, sino otros grupos de personas que tengan la idea y la pongan en marcha... creemos más en pequeñas estructuras independientes y no entrar a economía de escala y de mercado, que son macroestructuras, que al final acaban entrando en unas dinámicas que no sé si reproducen a los mismos mercados" (Mercatrèmol). En cambio, las segundas prefieren construir tales macroestructuras mediante redes de distribución gestionadas de forma centralizada: "Somos una empresa porque queremos dar esa imagen de que somos una empresa, nuestro proyecto era facilitar el consumo ecológico para el conjunto de la población, por lo menos en nuestra área de influencia de la provincia de Alicante. Querríamos tener un punto de venta en cada comarca para que toda la gente tenga acceso a la compra ecológica a un precio razonable" (Biotrèmol). Esta divergencia se puede identificar en las columnas correspondientes a cada uno de los GCE estudiados en los Cuadros no 2, 3, 5 y 6.

\section{Hacia la neo-convencionalización del consumo ecológico.}

Entre los tres casos estudiados, Bioalacant representa la fidelidad a los planteamientos fundacionales del movimiento por una alimentación agroecológica y Biotrèmol encarna la tendencia a la neo-convencionalización. Mercatrèmol está más cerca del primer caso, pero presenta algunos puntos concomitantes con el segundo, derivados de su origen común.

Bioalacant y Mercatrèmol sólo venden a sus socios como forma de mantener el espíritu de comunidad y la implicación de todos ellos en la gestión interna del grupo: "... el hecho de no abrirlo al público hace que la gente no se relaje" (Mercatrèmol).

73 Conill 2012 p.129 
No admiten el pago con tarjeta bancaria para eludir la intermediación financiera y el pago de comisiones. Su horario de apertura es sensiblemente más breve que el de Biotrèmol y la edad media de sus integrantes, en cambio, es mayor (48,5 y 46,9 años frente a 41,2). El compromiso personal de estos participantes con su GCE es muy elevado, hasta el punto de que los socios de Bioalacant nunca se han dado de baja, y ello pese a que la distancia entre sus domicilios y la granja es la mayor de todos los casos y, por ello, deben desplazarse siempre en automóvil particular. Esa mayor edad media se traduce en un importe medio de compra netamente superior, reflejo probable, a su vez, de una mayor proporción de la compra mensual familiar adquirida en el GCE.

En todas las afirmaciones del Cuadro no 5 ( salvo la nº 6), la valoración más alta corresponde a los miembros de Bioalacant, lo que pone en evidencia su perfil más concienciado respecto a las implicaciones no individuales de la alimentación ecológica. De forma significativa, son sus integrantes los únicos que otorgan una puntuación superior a 4 para las afirmaciones 11 y 12, las que expresan de forma más directa la voluntad personal de contribuir a la transformación social, política y ambiental. Y en el Cuadro $n^{\circ}$ 6, de nuevo, el porcentaje de personas que se identifican con la opción del activismo es del $26 \%$ en este grupo, y del 23\% en Mercatrèmol. La entrevista a Bioalacant señala que "hay otros criterios, los éticos y sociales, que sea gente que no solo produce ecológico, sino que está involucrado en el mundillo de la agricultura ecológica ¿por qué? Porque trabaja en el movimiento o porque, por lo menos es consumidor...no es un simple productor oportunista o es gente que no explota a la mujer o no explota inmigrantes, y si además está en alguna organización que tenga que ver con la economía alternativa y solidaria, pues mucho mejor. Esto quizás es como un pasito más difícil pero sí que lo buscamos".

En cambio, Biotrèmol muestra una orientación comercial y expansiva. Es una empresa cooperativa (no una asociación de consumidores, como los otros dos grupos) que dispone de cuatro puntos de venta al público, si bien los socios pueden disfrutar de precios entre un $20 \%$ y un $30 \%$ inferiores. De hecho, bajar precios para atraer compradores es una de las estrategias que la acercan a la distribución convencional. Estas tiendas ocupan ubicaciones atractivas: “Todas las tiendas son chaflán, luminosas y en esquina. Tenemos la misma imagen en todas las tiendas. En comparación con Mercadona u otras tiendas convencionales, que trabajan con mucha luz artificial ... somos todo luminoso porque queremos que el producto ecológico se asocie con luminosidad".

En consecuencia, el horario comercial es amplio (el triple que Bioalacant, tanto en horas como en días de apertura) y los establecimientos están cerca de los consumidores. Este despliegue espacial de la red comercial explica que los socios de Biotrèmol sean los que menos recurren al automóvil particular y los que menos han conocido el grupo por redes personales y más porque han pasado delante de la tienda. De hecho, en la tienda Biotrèmol de San Vicente del Raspeig, la venta a personas que no son miembros de la cooperativa y la alta presencia de estudiantes, debida a 
la proximidad con la Universidad de Alicante, influyen en la menor edad media de los consumidores, en el desplome del perfil político y activista y en que sea el único punto de venta de este estudio que actúe como una tienda de barrio.

Otro rasgo de neo-convencionalización de Biotrèmol es el uso de la tarjeta bancaria, al que recurren el $76 \%$ de sus socios. Esto encaja con su menor edad media, ya indicada, y su elevado nivel formativo: el $87 \%$ ha cursado estudios universitarios o de doctorado. En cambio, sus motivaciones para participar en el GCE difieren de las de Bioalacant de forma sustancial: sólo el 13\% de los socios se reconocen como activistas (Cuadro $\mathrm{n}^{\circ} 6$ ) y la salud preocupa al $61 \%$ de ellos, valor superior al de los demás grupos. En cuanto a las afirmaciones del Cuadro $\mathrm{n}^{\circ} 5$, solamente superan a las de Bioalacant en el caso de los productos locales $\left(\mathrm{n}^{\circ} 4\right)$ y conceden mucha menos importancia a los números 11 y 12, relacionados con la transformación.

Por último, estas diferencias en el perfil de los socios se trasladan a su propia visión sobre el funcionamiento del GCE. A la pregunta abierta “¿Cómo crees que podría funcionar todavía mejor esta asociación/cooperativa de consumidores?", las respuestas muestran dos planteamientos completamente diferentes. Algunos miembros abogan por fortalecer el voluntariado y la implicación personal, y añoran los inicios del grupo, cuando prácticamente todos los miembros eran activistas. Pero muchos otros comentarios comparten o reclaman lo que aquí denominamos neo-convencionalización del consumo ecológico, mediante la ampliación del surtido de productos frescos, la admisión del pago con tarjetas de crédito, la ampliación de los horarios, la reducción de los precios o la posibilidad de efectuar la compra por vía electrónica; asemejando estos espacios de consumo a la gran distribución comercial y convirtiendo estética y funcionalmente los GCE en tiendas propiamente dichas.

\section{Conclusiones}

Los datos disponibles demuestran que el consumo de alimentos ecológicos está creciendo en España. La distribución ecológica está adquiriendo un perfil que se aproxima progresivamente al de los alimentos convencionales porque los grandes supermercados están introduciendo estas referencias en sus lineales para rentabilizar el crecimiento del consumo y la disposición de muchos consumidores a pagar precios relativamente altos por esta clase de productos. En este contexto, los grupos de consumo ecológico, que mantienen una posición pequeña, pero estable, como canal de distribución directa entre productores rurales y consumidores urbanos, están sometidos a una creciente tensión. Por una parte, la fidelidad a los principios fundacionales (agroecología, soberanía alimentaria) explica que algunos GCE mantengan tamaños reducidos, surtidos de productos de proximidad y modos de gestión tradicionales, como el voluntariado, la rotación de tareas y la democracia directa. Por otro lado, la participación de nuevos miembros con valores más individualistas, relacionados con la salud personal y el bienestar familiar y que demandan un surtido más amplio y un servicio más cómodo, está orientado a ciertos GCE por la senda de la neo-convencionalización, es decir, la adopción de formas de organización 
y gestión semejantes a los que practica la distribución alimentaria hegemónica.

Los tres GCE estudiados en el área metropolitana de Alicante encarnan dicha tensión, que reproduce las categorías de Conill y otros ${ }^{74}$, sobre todo las dos primeras, los practicantes culturalmente transformadores (fieles a los objetivos y métodos de los primeros GCE) y los practicantes no capitalistas (que desean consumir alimentos ecológicos por motivos individuales, pero no les asignan un significado transformador). Barbeta ${ }^{75}$ y Alonso y otros ${ }^{76}$ han encontrado esta misma dicotomía en el mundo del consumo ecológico, pero sus trabajos se han desarrollado desde la Sociología y no inciden en las implicaciones que tienen ambas posturas sobre la organización interna de los GCE ni tampoco en las consecuencias geográficas de esta tensión.

En efecto, la participación en modelos como Bioalacant garantiza la conexión directa entre productor y consumidor y, con ella, la voluntad de construir una economía alimentaria localizada, de proximidad, autogestionada y con un intenso compromiso político. Esta solución territorial, al menos hasta ahora, no ha sido capaz de expandir su presencia social y económica ni de generar una red tupida de micro-circuitos de valor capaces de constituir una alternativa real a la hegemonía de la gran distribución. Aunque su funcionamiento interno satisfaga las aspiraciones de autonomía de sus integrantes, no contribuye a la visibilización del consumo ecológico alternativo y a su popularización como opción viable de consumo para grupos sociales con menos inquietudes políticas.

Parece que la opción encarnada por Biotrèmol es la que explica las afirmaciones oficiales sobre la creciente profesionalización de ciertos GCE como factor fundamental del crecimiento de este segmento del mercado de alimentos ecológicos. Las limitaciones cuantitativas y cualitativas de la oferta de los GCE más tradicionales está impulsando una segunda solución territorial, nacida y heredera de la anterior, pero parcialmente hibridada con el canal comercial más convencional por lo que se refiere a la variedad de los productos, la procedencia geográfica de los mismos, el horario de apertura, las formas de pago y el despliegue de su red de puntos de venta. La preocupación por la salud, argumento principal de los miembros de este tipo de GCE, está probablemente más extendida en la sociedad que la crítica radical al sistema capitalista. Por tanto, parece comprensible que esta segunda solución, la neo-convencionalización de los GCE, menos localizada, menos comunitaria y menos sostenible, esté ganando adeptos con rapidez.

Naturalmente, es preciso continuar analizando la trayectoria de los GCE para averiguar la consistencia de estas dos opciones que se dibujan en el mundo de la alimentación ecológica alternativa. Los GCE de mayor dimensión, como se acaba de indicar, nacen de las primeras propuestas comunitarias, autogestionadas y con vocación política. Es relevante, por tanto, estudiar la génesis de los GCE, sus contextos geográficos, y los vínculos que se establecen entre las iniciativas de una misma

74 Conill y otros 2012 p.129

75 Barbeta 2014 p. 84

76 Alonso y otros 2014 p. 21 
ciudad para conocer mejor cuál es el punto de inflexión o de acumulación de oferta y de demanda a partir del cual es posible la aparición y consolidación de estas soluciones híbridas o neo-convencionales que parecen capaces de ampliar la base social del consumo ecológico alternativo. En segundo lugar, resulta fundamental analizar la oferta de productos que distribuyen estos GCE para determinar su capacidad de transformarse en alternativas integrales de consumo sostenible. Hasta el momento, la mayor parte de la oferta de los GCE consiste en alimentos frescos y algunos envasados, como se ha indicado ya. La incorporación de productos de cosmética, limpieza o vestido, presentes también en algunos casos, puede incrementar su volumen de actividad, reforzar la neo-convencionalización y relegar a los grupos más apegados al modelo fundacional a una posición testimonial, a la vez que fortalecer la condición alternativa de estos nuevos GCE frente a la distribución ecológica organizada. Por último, una aproximación geográfica a todo este proceso de transformación de los GCE exige conocer con más detalle su red de proveedores, un aspecto habitualmente poco considerado en la literatura: la ubicación de dichos proveedores, la capacidad de los GCE para asegurarles unos ingresos dignos y los requisitos que los GCE exigen a los productos que distribuyen son algunas de las variables que habrá que considerar en una evaluación crítica de su contribución a la construcción de una economía más localizada, más equitativa, más sostenible y, sobre todo, capaz de erigirse en una alternativa consistente a las cadenas de valor del capitalismo agroindustrial hegemónico.

\section{Bibliografía:}

ALONSO, L.E.; FERNÁNDEZ, C.J. \& IBÁÑEZ, R. Crisis y nuevos patrones de consumo: discursos sociales acerca del consumo ecológico en el ámbito de las grandes ciudades españolas. EMPIRIA - Revista de Metodología de Ciencias Sociales, 2014, no 29; p. 13-38.

Disponible en Internet: <https://doi.org/10.5944/empiria.29.2014.12939>

ARGÜELLES, L.; ANGELOVSKI, I. \& DINNIE, E. Power and privilege in alternative civic practices: Examining imaginaries of change and embedded rationalities in community economies. Geoforum, 2017, no 86, p. 30-41.

Disponible en Internet: <https://doi.org/10.1016/j.geoforum.2017.08.013>

BARBETA, M. De los vínculos en el consumo al consumo en los vínculos: análisis de las formas de sociabilidad en las prácticas de consumo ecológico. Revista Española de Sociología, 2014, n² 22, p. 67-95.

Disponible en Internet: <http://www.socioeco.org/bdf_fiche-document-3625_ es.html>

BUCK, D.; GETZ, CH. \& GUTHMAN, J. From farm to table: the organic vegetable commodity chain of Northern California. Sociologia Ruralis, 1997, n 37, 3-20. Disponible en Internet: <https://onlinelibrary.wiley.com/doi/ epdf/10.1111/1467-9523.00033> 
CAHILL, S.; MORLEY, K. \&- POWELL, D.A. Coverage of organic agriculture in North American newspapers: media linking food safety, the environment, human health and organic agriculture. British Food Journal, 2010, n 112, p. 710-722. Disponible en Internet: <https://doi.org/10.1 108/00070701011058244>

CALVÁRIO, R. \& KALLIS, G. Alternative Food Economies and Transformative Politics in Times of Crisis: Insights from the Basque Country and Greece. Antipode, 2017, no 49, p. 597-616.

Disponible en Internet: <https://onlinelibrary.wiley.com/doi/pdf/10.1111/ anti.12298>

CONILL, J. y OTROS. Otra vida es posible: prácticas económicas alternativas durante la crisis. Barcelona: Editorial UOC, 2012.

COMISIÓN EUROPEA. Reglamento 2092/91 sobre la producción orgánica de productos agrícolas e indicaciones relativas a los productos agrícolas y alimentarios, 1991.

Disponible en Internet: <https://eur-lex.europa.eu/LexUriServ/LexUriServ. do?uri=CONSLEG:1991R2092:20080514:EN:PDF> [10 de octubre de 2018].

COMISIÓN EUROPEA. Reglamento 834/2007 sobre la producción orgánica y el etiquetado de los productos orgánicos, derogando el Reglamento 2092/91, 2007. Disponible en Internet: <https://eur-lex.europa.eu/LexUriServ/LexUriServ. do?uri=OJ:L:2007:189:0001:0023:EN:PDF> [06 de junio de 2018].

ESPINOSA SEGUÍ, A. El papel de los grupos de consumo agroecológico en la construcción de un sistema de distribución y un orden alimentario alternativos. En SÁNCHEZ HERNÁNDEZ, J.L. (Coordinador). Espacios y prácticas económicas alternativas en las ciudades españolas. Cizur Menor (Navarra): Thomson Reuters Aranzadi, 2019, p. 39-54.

EVANS, D. Consuming conventions: sustainable consumption, ecological citizenship and the worlds of worth. Journal of Rural Studies, 2011, $\mathrm{n}^{\circ} 27$, p. 109-115. Disponible en Internet: <https://doi.org/10.1016/j.jrurstud.2011.02.002>

FiBL \& IFOAM. The World of Organic Agriculture. Statistics and Emerging Trends, 2018. Research Institute of Organic Agriculture (FIBL), Frick - IFOAM-Organics International, Bonn, 2018.

Disponible en Internet: <http://www.organic-world.net/yearbook/ yearbook-2018/pdf.html> [23 de septiembre de 2018].

FUENTES, C. \& LÓPEZ DE COCA, E. El consumo de alimentos ecológicos. Distribución y Consumo, 2008, no 99 , p. 5-24.

Disponible en Internet: <http://mercasa.proyectos.factoriadeinnovacion.com/ files/multimedios/1288217106_1288118325_DYC_2008_99_5_24.pdf> 
GONZÁLEZ ROMERO, G. \& TORRES GUTIÉRREZ, J. Dimensión territorial y caracteres socioespaciales de las practicas económicas alternativas. Aproximación a partir del análisis comparado de casos. En SÁNCHEZ HERNÁNDEZ, J.L. (Coordinador). Espacios y prácticas económicas alternativas en las ciudades españolas. Cizur Menor (Navarra): Thomson Reuters Aranzadi, 2019, p. 257-276.

GOODMAN, D.; GOODMAN, M.K. Alternative food networks. En KITCHIN, R. Y THRIFT, N. (coordinadores). International Encyclopedia of Human Geography, Elsevier, p.208-220.

GÖTZE, F.; MANN, S.; FERJANI, A.; KOHLER, A. \& HECKELEI, Th. Explaining market shares of organic food: evidence from Swiss household data. British Food Journal, 2016, nº 118, p. 931-945.

Disponible en Internet: <https://doi.org/10.1 108/BFJ-09-2015-0318>

GRIVINS, M.; KEECH, D.; KUNDA, I. \& TISENKOPFS, T. Bricolage for Self-Sufficiency: An Analysis of Alternative Food Networks. Sociologia Ruralis, 2017, n 57, p. 340-356.

Disponible en Internet: <https://doi.org/10.1111/soru.12171>

GUTHMAN, J. Regulating meaning, appropriating nature: the codification of Californian organic agriculture. Antipode, 1998, nº 30, p. 135-154.

Disponible en Internet: <https://doi.org/10.1111/1467-8330.0007l>

GUTHMAN, J. The trouble with 'organic lite' in California: a rejoinder to the 'conventionalisation' debate. Sociologia Ruralis, 2004, nº 44, p. 301-316.

Disponible en Internet: <https://doi.org/10.1111/j.1467-9523.2004.00277.x>

ILBERY, D. \& KNEAFSEY, M. Product and place: promoting quality products and services in the lagging rural regions of the European Union. European Urban and Regional Studies, 1998, nº 5, p. 329-341.

Disponible en Internet: <https://doi.org/10.1177/096977649800500404>

JANSSEN, M. \& HAMM, U. The mandatory EU logo for organic food: consumer perceptions. British Food Journal, 2012, no 114 , p. 335-352.

Disponible en Internet: < https://doi.org/10.1108/00070701211213456>

LÓPEZ, D. Canales cortos de comercialización como elemento dinamizador de las agriculturas ecológicas urbana y periurbana. I Congreso Estatal de Agricultura Ecológica Urbana y Periurbana. Elche, 6 y 7 de marzo de 2011 , organizado por la Sociedad Española de Agricultura Ecológica (SEAE).

Disponible en Internet: <https://revistasoberaniaalimentaria.wordpress. com/2012/01/28/canales-cortos-de-comercializacionun-elementodinamizador/>

LÓPEZ, D. Producir alimentos, reproducir comunidad: redes alimentarias alternativas como formas para la transición social y ecológica. Madrid: Libros en Acción, 2015.

LÓPEZ, D., ALONSO, N. \& HERRERA, P.M. Políticas alimentarias urbanas para la sostenibilidad. Análisis de experiencias en el Estado español, en un contexto internacional. Fundación Entretantos, 2018. 
MAPA DE INNOVACIÓN SOCIAL DE CATALUÑA [en línea].

Disponible en Internet: <https://barrisicrisi.wordpress.com/category/mapainnovacio-social/> [13 de julio de 2018].

MAYE, D.; HOLLOWAY, L. \& KNEAFSEY, M. eds. Alternative food geographies. Representation and practice. Amsterdam: Elsevier, 2007.

MÉNDEZ, R. Prácticas económicas alternativas y nuevas dinámicas: los grupos de consumo agroecológico. En DELGADILLO, J. y SANZ, J. (coordinadores). Sistemas agroalimentarios locales de proximidad en contextos rururbanos en México y España. México: Universidad Nacional Autónoma de México, 2017, p. 21-42.

MÉNDEZ, R. \& MONTESERÍN, O. Redes alimentarias alternativas en grandes ciudades: los mercados de productores agrarios en Madrid. Cuadernos Geográficos, 2017, no 56, p. 193-216.

Disponible en Internet: <http://revistaseug.ugr.es/index.php/cuadgeo/article/ view/4049>

MICHELINI, J.J.; MÉNDEZ, R. \& ABAD, L.D. Movilización social y alternativas alimentarias en áreas urbanas: los grupos de consumo agroecológico en Madrid. Ciudad y Territorio - Estudios Territoriales, 2017, nº 194, p. 679-698.

MINISTERIO DE ALIMENTACIÓN, AGRICULTURA Y MEDIO AMBIENTE. Canales cortos de comercialización en el sector agroalimentario. Madrid: MAGRAMA, 2013.

Disponible en Internet: <http://www.mapama.gob.es/es/alimentacion/ temas/estrategia-mas-alimento-menos-desperdicio/Estudio_CCC\%20con\%20 observaciones_tcm30-78860.pdf> [13 de julio de 2018].

MINISTERIO DE ALIMENTACIÓN, AGRICULTURA Y MEDIO AMBIENTE. Evolución de la caracterización de la tipología y perfil sociodemográfico del consumidor de alimentos ecológicos en España. Madrid: MAGRAMA, 2014.

Disponible en Internet: <http://www.mapama.gob.es/es/alimentacion/temas/ produccion-ecologica/estudioperfilconsumidorecologico2014_tcm30-79364. pdf $>$ [ 13 de julio de 2018].

MINISTERIO DE ALIMENTACIÓN, AGRICULTURA Y MEDIO AMBIENTE. Caracterización de la comercialización y distribución de productos ecológicos a través de los canales de venta especializados. Madrid: MAGRAMA, 2015

Disponible en Internet: <http://www.mapama.gob. e s / e s / a li m e n t a ci on / t e ma s / p r od u c c i on-e cologi ca / estudiocaracterizacioncomercializacioncanalesventaespecializados_tcm 30379455.pdf $>$ [ 13 de julio de 2018].

MINISTERIO DE AGRICULTURA Y PESCA, ALIMENTACIÓN Y MEDIO AMBIENTE. Caracterización de la producción ecológica española en términos de valor y mercado, referida al año 2015. Madrid: MAPAMA, 2016.

Disponible en Internet: <http://www.mapama.gob.es/es/alimentacion/ temas/produccion-ecologica/informecaracterizacionpecologica 2015 definitivo-271216_tcm7-443642_tcm30-379445.pdf> [13 de julio de 2018]. 
MINISTERIO DE AGRICULTURA, PESCA, ALIMENTACIÓN Y MEDIO AMBIENTE. Caracterización de compradores de productos ecológicos en canal especializado. Madrid: MAPAMA, 2017a.

Disponible en Internet: <http://www.mapama.gob. e s / e s / a li m en ta ci o n / t e m a s / p r o d u c c i o n - e c o logi c a / caracterizaciondecompradoresecologicosencanalespecializadojul17_tcm 30419446.pdf> [25 de septiembre de 2018].

MINISTERIO DE AGRICULTURA, PESCA, ALIMENTACIÓN Y MEDIO AMBIENTE. Definición y evaluación de estrategias de potenciación de la capacidad de interlocución y vertebración del sector de la producción ecológica en España. Madrid: MAPAMA, 2017b.

Disponible en Internet: <http://www.mapama.gob.es/es/alimentacion/ temas/produccion-ecologica/informevertebracionsectorecologicoano2016informefinal-definitivo_tcm30-437293.pdf> [26 de octubre de 2018].

MORAGUES, A. Emancipatory or Neoliberal Food Politics? Exploring the 'Politics of Collectivity' of Buying Groups in the Search for Egalitarian Food Democracies. Antipode, 2017, no 49, p. 455-476.

Disponible en Internet: <https://doi.org/10.1111/anti.12274>

MORAGUES, A. \& MARSDEN, T. The political ecology of food: Carving 'spaces of possibility' in a new research agenda. Journal of Rural Studies, 2017, n 55, p. 275-288.

Disponible en Internet: <https://doi.org/10.1016/j.jrurstud.2017.08.016>

MUNDUBAT. Circuitos cortos de comercialización en Euskal Herria. Bilbao: EHNE, 2012.

Disponible en Internet: <http://pae.gencat.cat/web/.content/al_alimentacio/ al01_pae/05_publicacions_material_referencia/arxius/circuitoscortos_ euskalherria.pdf>

MUTERSBAUGH, T.; KLOOSTER, D.; RENARD, M.C. \& TAYLOR, P. Certifying rural spaces: quality-certified products and rural governance. Journal of Rural Studies, 2005, no 21, p. 381-388.

Disponible en Internet: <https://doi.org/10.1016/j.jrurstud.2005.10.003>

MUNUERA ALEMÁN, J.L. \& PEMARTIN GONZÁLEZ-ADALID, M. El consumidor europeo de productos ecológicos. Primeros resultados de un estudio cualitativo del consumidor español. Distribución y Consumo, 2005, nº 84, p. 50-64.

Disponible en Internet: <http://www.mercasa.es/files/ multimedios/1290789118_DYC_2005_84_50_63.pdf>

PARROTT, N., WILSON, N. \& MURDOCH, J. Spatializing quality: regional protection and the alternative geography of food. European Urban and Regional Studies, 2002, no 9, p. 241-261.

Disponible en Internet: <https://doi.org/10.1177/096977640200900304> 
PASCUAL RUIZ-VALDEPEÑAS, H., GIL ÁlVAREZ, E., \& GUERRA VELASCO, J.C. Práctica social, economía alternativa y espacios de proximidad en la ciudad de Valladolid. Recerca. Revista de Pensament y Anàlisi, 2018, No 23, 193-218.

Disponible en Internet: <http://www.e-revistes.uji.es/index.php/recerca/ article/view/2809/2897>

PASCUAL RUIZ-VALDEPEÑAS, H. \& GUERRA VELASCO, J.C. La base social y las formas de organización de las practices económicas alternativas. Una aproximación a su caracterización, estrategias, potencialidades y límites. En SÁNCHEZ HERNÁNDEZ, J.L. (Coordinador). Espacios y prácticas económicas alternativas en las ciudades españolas. Cizur Menor (Navarra): Thomson Reuters Aranzadi, 2019, p. 233-255.

ROSIN, Ch. The conventions of agri-environmental practice in New Zealand: farmers, retail driven audit schemes and a new spirit of farming. GeoJournal, 2008, $\mathrm{n}^{0} 73$, p. 45-54.

ROSSET, P. \& ALTIERI, M.A. Agroecología. Ciencia y Política. Barcelona: Icaria, 2018. SÁNCHEZ HERNÁNDEZ, J.L. Redes alimentarias alternativas: concepto, tipología y adecuación a la realidad española. Boletín de la Asociación de Geógrafos Españoles, 2009, nº 49, 185-207.

Disponible en Internet: <http://www.age-geografia.es/ojs/index.php/bage/ article/view/781/704>

SÁNCHEZ HERNÁNDEZ, J.L. \& PITARCH GARRIDO, MaD. Las modalidades, el alcance y los límites del giro alternativo de las políticas urbanas en España. En SÁNCHEZ HERNÁNDEZ, J.L. (Coordinador). Espacios y prácticas económicas alternativas en las ciudades españolas. Cizur Menor (Navarra): Thomson Reuters Aranzadi, 2019, p. 277-295.

SANZ, J.; LAGOMA, C. \& LOZENKO, A. Los grupos y cooperativas de consumo agroecológico de Lavapiés, Madrid:política, organizacióny gobernanza territorial. En DELGADILLO, J. y SANZ, J. (coordinadores). Sistemas agroalimentarios locales de proximidad en contextos rururbanos en México y España. Méjico: Universidad Nacional Autónoma de México, 2017, p. 43-72.

SURIÑACH, R. Economías transformadoras de Barcelona. Barcelona: Montaber, 2017.

THØGERSEN, J.; PEDERSEN, S.; PATERNOGA, M.; SCHWENDEL, E. \& ASCHEMANNWITZEL, J. How important is country-of-origin for organic food consumers? A review of the literature and suggestions for future research. British Food Journal, 2017, no 119 , p. 542-557.

Disponible en Internet: <https://doi.org/10.1 108/BFJ-09-2016-0406>

VARIOS AUTORES. Arraigar las instituciones. Propuestas de políticas agroecológicas desde los movimientos sociales. Madrid: Libros en Acción, 2017. 
VEGA, M.;TORRES, F.J.\& GUTIÉRREZ, M.Influencia delas variables sociodemográficas en el consumo de alimentos ecológicos en España: análisis con base en el panel de consumo alimentario del MARM. Revista Española de Estudios Agrosociales y Pesqueros, 2011, n² 230, p. 147-170.

Disponible en Internet: <http://www.mapama.gob.es/app/publicaciones/art_ datos_art.asp?articuloid=1318\&codrevista=REEAP>

VIVAS, E. Consumo agroecológico. Una opción política. Viento Sur, 2010, nº 108, 5463.

Disponible en Internet: <https://www.vientosur.info/spip.php?article31 14 > VIVAS, E. El negocio de la comida. ¿Quién controla nuestra alimentación? Barcelona: Icaria, 2014.

WILLER H. \& YUSSEFI, M. Organic World Agriculture World-Wide. Bad Dürkheim: Stiftung Ökologie \& Landbau, 2000.

Disponible en Internet: <http://orgprints.org/1000/1/willer-yussefi-2000-01world-of-organic.pdf >

WHITWORTH, E.; DRUCKMAN, A. \& WOODWARD, A. Food scares: a comprehensive categorisation. British Food Journal, 2017, no 119, p. 131-142.

Disponible en Internet: <https://doi.org/10.1108/BFJ-06-2016-0263>

ZANOLI, R.; GAMBELLI, D. \& VAIRO, D. Scenarios of the organic food market in Europe. Food Policy, 2012, no 37, p. 41-57.

Disponible en Internet: <https://doi.org/10.1016/j.foodpol.2011.10.003>

(C) Copyright: José Luis Sánchez y Ana Espinosa, 2020

(c) Copyright: Scripta Nova, 2020.

Ficha bibliográfica:

SÁNCHEZ, José Luis; ESPINOSA, Ana. ¿Alternativa o adaptación? los grupos de consumo de alimentos ecológicos en el área urbana de Alicante. Scripta Nova. Revista Electrónica de Geografía y Ciencias Sociales. Barcelona: Universidad de Barcelona, 15 de Mayo de 2020, vol. XXIV, nº 638. [ISSN: 1138-9788] 